\title{
“I'M STILL FIGHTING FOR THE TWO OF US": HOW PARTNERS OF UK VETERANS CONSTRUCT THEIR EXPERIENCE OF LIVING WITH COMBAT- RELATED TRAUMA
}

\author{
Emily Doncaster ${ }^{\mathrm{a}}$, Leanne Andrews ${ }^{\mathrm{a}}$, Syd Hiskey $^{\mathrm{b}}$, Susan McPherson $^{\mathrm{a}}$ \\ ${ }^{a}$ School of Health and Social Care, University of Essex, Colchester CO4 3SQ \\ ${ }^{\mathrm{b}}$ Consultant Clinical Psychologist, NHS
}

\begin{abstract}
There has been little qualitative research into the experiences of UK partners of veterans with PTSD. This study therefore aimed to explore how partners constructed their experiences of living with the condition. Fifteen female partners of male UK veterans were recruited and interviewed. Using a social constructionist thematic analysis, five themes were constructed: the women's need to subdue own emotional and behavioural responses; dilemmas about whether the veteran was unwell or 'bad'; attempts at negotiating multiple roles; challenging the narrative of veterans as heroes; and the relational struggle with the transition to nonmilitary life. This study highlighted the importance of considering the veteran as existing within a relational and cultural context, and the need to include partners in therapeutic interventions.
\end{abstract}

Key Words: posttraumatic stress disorder; secondary traumatic stress; couple relationship; military veterans; qualitative research 


\section{“I'M STILL FIGHTING FOR THE TWO OF US": HOW PARTNERS OF UK VETERANS CONSTRUCT THEIR EXPERIENCE OF LIVING WITH COMBAT- RELATED TRAUMA}

The mental health of combat veterans is an area that has received decades of interest from academics, clinicians, the military, and society alike, with a particular emphasis on combat-related traumatic stress or post-traumatic stress disorder (PTSD). While such attention is warranted due to the severity and wide-ranging impact that traumatic events during combat have been reported to have on some veterans, much of the research has focused on the symptomatology and experiences of the veterans themselves - although importantly the body of literature into the relational elements of trauma is growing (Nelson \& Wright, 1996; Goff \& Smith, 2005). This is a crucial area of research because it is not solely the individual who is affected by the psychological impact of combat exposure, as a significant proportion of veterans will be returning to live with their families. Maintaining a purely individual lens when researching or working clinically with traumatised veterans (and their families) neglects to address the potential systemic and relational impact of how trauma might affect each family member, and also means opportunities may be missed in terms of how clinicians may best support and intervene in such cases.

There is an increasing body of evidence from a number of countries to suggest that partners are affected by living with a veteran who is experiencing symptoms of PTSD/traumatisation. Spouses have been found to experience high levels of stress, depression (Manguno-Mire et al., 2007), symptoms of PTSD, anxiety (Westerink \& Giarratano, 1999), adjustment disorders, relationship dissatisfaction (Lambert, Engh, Hasbun, \& Holzer, 2012), burnout/caregiver burden (Solomon, Dekel, Zerach, \& Horesh, 2009; Klarić et al., 2010), and more somatic problems (Dirkzwager, Bramsen, Ader, \& van der Ploeg, 2005). More recently in the UK, partners of veterans were found to report difficulties with 
alcohol, depression, generalised anxiety disorder and probable PTSD (Murphy, Palmer, \& Busuttil, 2016).

Just as the veterans' trauma/PTSD symptoms do not exist in a vacuum (Figley, 1995), the same also holds true for the so-called 'secondary symptoms' of PTSD/trauma or 'secondary traumatisation' that has been reported in partners of military veterans - meaning that both members of a couple will be impacted by the emotional experiences of the other.

Other related terms used to describe such a phenomenon include 'vicarious traumatisation', 'contagion' (e.g. Maltas, 1996), and 'compassion fatigue' to name a few. For a more detailed outline of these concepts and their overlap, see Klarić, Kvesić, Mandić, Petrov and Francišković (2013). There have also been attempts to understand why partners might be impacted by combat-related trauma despite not having experienced it directly. Some of these are outlined briefly below.

\section{Communication and empathy}

Maloney (1988) suggested that the process of secondary traumatisation involves family members over-empathising with the primary trauma survivor and their experiences, so much so that they begin to internalise the individual's feelings, memories and beliefs as their own (Nelson-Goff \& Smith, 2005; Dekel \& Monson, 2010). The potential for affective empathy to act as a risk factor for increased psychological distress in female partners of veterans has been reported (Dekel, Siegel, Fridkin, \& Svetlitzky, 2017). An alternative mechanism is that indirect exposure to the traumatic event, for example by the veteran talking in detail about what happened, can result in the partner developing their own stress reaction.

\section{Caregiver burden}

Living with trauma is likely to be a relational challenge that forces, requires or demands a shift in patterns of behaviour for both parties within the relationship. Various studies have discussed the observation that the partner who did not directly experience the 
trauma may feel drawn towards over-responsibility and over-functioning in the relationship, perhaps in an attempt to protect the traumatised individual and limit any unnecessary demands by lessening the roles they are expected to fulfil within the home (e.g. Gilbert, 1997; Lyons, 2001; Nir, Ebadi, Khoshknab, \& Tavallaie, 2013; Vagharseyyedin, 2014). As well as potentially maintaining some of the individual's difficulties, this is likely to also become overly demanding for the partner taking on the caring/responsible role. This behavioural negotiation can be understood as an example of systemic homeostasis and the associated pull to maintain a stable and familiar dynamic within the family system.

Indeed, partners of veterans with PTSD have been found to report high levels of caregiver burden (e.g. Calhoun, Beckham, \& Bosworth, 2002; Dekel, Solomon, \& Bleich, 2005), which may be responsible for some of their emotional distress.

\section{Figley's Trauma Transition Model}

Figley $(1983 ; 1986 ; 1993 ; 1995 ; \& 2009)$ has written widely about the impact of trauma on the family system and has proposed different ways whereby partners and other family members may become affected by traumatic events experienced by one individual. One way is chiasmal or secondary trauma, when the traumatisation initially experienced by one member appears to infect others within the system, who begin to show their own emotional distress and trauma symptoms. Figley stated that this is most relevant to families of veterans diagnosed with PTSD.

In terms of why family members become traumatised, similar to Maloney (1988), Figley stated that family members' emotional closeness puts them in the position of being effective healers of trauma, but also at risk of developing symptoms themselves. $\mathrm{He}$ concluded that: "their strength as well as their Achilles' heel is empathy" (Figley, 1986, p. 48).

The Couple Adaptation to Traumatic Stress (CATS) model 
More recently, Nelson-Goff and Smith (2005) adopted Figley's conceptualisation of secondary traumatic stress and developed their systemic theory of trauma in couples. They argued that although there is support for the secondary traumatisation hypothesis within the literature, its limitation is that it does not fully explain the interaction between individual trauma symptoms and marital problems, or the specific mechanisms underlying how trauma impacts interpersonal functioning. This prompted them to develop the Couple Adaptation to Traumatic Stress (CATS) model (Nelson-Goff \& Smith, 2005) which suggested that the couple's experience of trauma relies on an interaction among: both individuals' current level of functioning (including behavioural, cognitive, emotional and biological symptoms); their own predisposing factors (such as previous trauma history, age and resources); and couple functioning (attachment, power, communication, conflict, roles, etc.). Importantly, they stressed that there is a bidirectional relationship between each factor, which means that each have the ability to influence the expression of trauma symptoms in the other. For example, it may be that the veteran within the couple is experiencing difficulties with physical contact or communication following their trauma, which results in their partner withdrawing and feeling depressed by the veteran's avoidance of intimacy, which in turn maintains and worsens the veteran's difficulties.

\section{Critique of the secondary traumatic stress concept}

The idea of secondary traumatic stress, however, has not been understood in the same way by all researchers, leading to conceptual differences in how it has been applied across the field. Some researchers (e.g. Frančišković et al., 2007) regard it as being analogous to the DSM-IV-TR (APA, 2000) or DSM-5 (APA, 2013) definitions of PTSD, whereby the partner experiences a trauma (either directly or indirectly) and suffers re-experiencing, avoidance and hyper-arousal as a result. Alternatively, other researchers have conceptualised secondary traumatic stress as potentially involving a much broader range of emotional and relational 
distress, such as low mood, anxiety, OCD and somatisation (e.g. Arzi, Solomon, \& Dekel, 2000), leading to a more inclusive, general definition. Renshaw et al. (2011) explored this quantitatively by exploring the symptoms of 190 wives of male service members/veterans, and found that the majority of women were experiencing general distress (e.g. feeling tense and dissatisfied with life), although a sub-section were experiencing symptoms in line with a PTSD-consistent presentation. Although these two positions are conceptually different, these authors noted that the term secondary traumatisation is often used in the trauma literature to refer to both constructs (Galovski \& Lyons, 2004; Renshaw et al., 2011). This is potentially a limitation as each construct contains within it different assumptions as to the process whereby partners are affected by living with trauma.

In conclusion, the majority of research in the area of veterans' mental health has employed a quantitative design (focused on symptoms of PTSD or secondary traumatic stress), and has been focused on the experiences of male personnel. Additionally, within the UK at least, most studies have concentrated their efforts on exploring the impact of deployment and trauma on the veteran themselves. This means that there is currently a need to expand research into how civilian partners may be affected by living with a veteran who is experiencing a significant reaction to trauma (Fossey, 2012). This study therefore aimed to explore how partners of UK veterans with PTSD/trauma symptoms constructed the impact the condition has on them, the veteran, and their relationship, employing a qualitative methodology.

\section{METHOD}

We recruited participants via the UK organisation, Combat Stress, a charity that works with veterans and reservists from the Armed Forces who experience mental health difficulties. They provide treatment for psychological problems, information and support for 
veterans and their families. We also recruited participants via Ripple Pond, a peer-led charity that runs support groups for adult family members of injured servicemen and women, and also supports affected individuals with setting up their own local groups. These organisations sent information about the study via email and social media to members and followers. Once potential participants expressed an interest, they were sent the longer study information sheet and consent form, and telephoned to discuss the study and to arrange the interview.

Fifteen participants were recruited. All were female partners in a relationship with a male veteran (despite the study being open to individuals in same-sex relationships) and who met the inclusion criteria that they were currently in a relationship with their veteran partner and had been for at least two years (mean length 17 years [SD $=13.8]$; range $2-45$ years). The women perceived that their veteran partner was experiencing a problematic reaction to combat-related trauma, which may or may not have been formally diagnosed as PTSD. For those men who had received a formal diagnosis, the women explained that these were given either by NHS mental health services, Combat Stress (UK military charity), or the military health service. In terms of the veterans, they had all been involved in active service for the British Armed Forces and were no longer currently serving. Nine of the couples had been in a relationship during the time in which the veteran was serving and the other six met after the veteran had already left the Forces. Twelve of the couples were married. See Tables 1 and 2 for other demographic information.

\{Tables 1 and 2 about here

We used an interview topic guide (see supplemental file) that outlined the general areas that would be covered during the interview. Specific questions were tailored to the individual in each interview. Participants were provided with an information sheet and consent form, and a list of contacts for support services for veterans and their families. They were offered a $£ 10$ general merchandise voucher for their participation. 
We transcribed the interviews verbatim and de-identified the data before analysis. We then undertook thematic analysis of the data within a social constructionist framework, which allowed for consideration of the researcher's role in the co-construction of these accounts. The specific structured method of thematic analysis we used for the analysis was that outlined by Braun and Clark (2006; Braun \& Clarke, 2012, 2013). This approach indicates six phases which we followed during the analysis stage: Phase 1: 'Familiarisation with the data' (this involved listening to the audio-recordings of the interviews and reading over the transcripts to begin to note key themes and ideas); Phase 2: 'Generation of initial codes' (we coded each transcript systematically, using a combination of both sematic [i.e. staying close to the more obvious content of the text] and latent [i.e. underlying assumptions and interpretation of the semantic content] codes; Phase 3: 'Generating themes' (we analysed the coded data across the whole data set and constructed themes); Phase 4: 'Reviewing themes' (this involved making sure that the themes still adequately represented the coded data extracts within them, and the themes were reviewed in relation to the interviews as a whole in terms of whether they sufficiently told the story of the data); Phase 5: 'Defining and naming themes' (we ensured the themes were distinct but related, describing the boundaries of each and any relationship to other themes); Phase 6: 'Producing the report' (we wrote up the themes in a coherent narrative which represented the story told within the data set).

To assure credibility of the analysis, one of the research supervisors coded a transcript which was then triangulated with the interpretation of the principal researcher (also the main coder). In the spirit of the constructionist epistemology underlying this research, each individual's interpretation was not deemed 'right' or 'wrong' but this process allowed for occasions to be identified where the analysis did not appear to represent an element of the (semantic or latent) content of the data. Research supervisors were also involved in reviewing the themes (via discussion of the coding frame) to provide a further element of triangulation. 
We also utilised the technique of negative case analysis whereby efforts were made to identify extracts that challenged a particular idea or theme; this helped us to remain open to considering the data from different angles.

In terms of data saturation, although it can be difficult to ascertain when this point is reached, we felt that by the last three interviews we were not assigning a significant number of new data codes, and the initial theme structure appeared to adequately represent these participants' stories. This therefore felt like an appropriate stage to stop recruitment.

Confirmability relates to the research process and analysis being relatively 'value-free' and not unduly influenced by the researcher's biases. However, research from a constructionist perspective posits that it is impossible to remove the influence of the researcher from the process, and in fact, this adds to the richness of the findings rather than detracts from it. Indeed, this epistemological position suggests that 'knowledge' and 'reality' are constructed in the interaction between interviewer and respondent (Burr, 2003). It is essential though that the researcher maintains a reflexive stance throughout and acknowledges the role that their previous experiences, background, preferences and assumptions have on the co-construction of knowledge (Mays \& Pope, 2000). The principal researcher used a reflective research diary to facilitate this process.

\section{RESULTS}

The principal researcher (a female clinical psychologist) interviewed the fifteen participants. The length of the interviews ranged from 52 minutes to 112 minutes, and were 75 minutes on average.

We identified five themes (see Table 3) which are described below and are supported by excerpts from the participants' accounts. 
\{Table 3 about here $\}$

“Walking on eggshells": Subduing own emotional and behavioural responses

The women frequently constructed a process whereby they acted to avoid conflict or triggering of their partners' trauma/PTSD symptoms by actively subduing their own responses. This included both emotional responses - for example, not displaying their own distress for fear of upsetting the veteran, and behavioural - such as walking away from an argument and 'backing down' rather than continuing with putting their own point across. This was particularly the case for dealing with anger, where the women felt it necessary to keep a balance on the level of emotional expression in the household and to try and have some control over the number of angry outbursts. For Jane, her self-monitoring was linked to a sense of inevitability over interactions ending in conflict:

It's very difficult because it's, what I would say is, walking on eggshells all the time, I have to watch what I'm saying all the time because I know what it'll be like if I say the wrong thing, it just all explodes, it erupts once again and I never know what to say, I never know what to do because I know what I do is wrong.

In addition to trying not to provoke anger, the women also changed the way they reacted during arguments in an attempt to lessen the impact on themselves and their partners, usually minimising the extent to which they retaliated. For example, Elsa responded to being verbally insulted by her husband through using passive methods - "I have only defended myself by withdrawing, not by attacking him" - which was constructed as being less provocative and more submissive. However, some women also acknowledged the systemic, bidirectional impact of their behaviour in that these seemingly passive methods of dealing with conflict were sometimes perceived by their veteran partners as being just as powerful as 
'fighting back', as the men were able to sense the women withdrawing and being less connected with the relationship.

Interestingly, there were other parallels between the nature of the veterans' trauma symptoms and some of the women's psychological experiences. For example, the process of self-monitoring and of carefully paying attention to the veterans' reactions and moods meant that the women often displayed significant hyper-vigilance themselves, a 'symptom' that underpins the diagnostic criteria for PTSD. However, their hyper-vigilance tended to be linked to current concerns about the veteran and protecting other family members (particularly children), rather than due to past traumatic events. It, however, was equally demanding on the women and they reported feeling on edge, and felt - similarly to symptoms underlying the PTSD construct - that something bad was about to happen.

Complete monitoring, you would- a Sunday dinner for instance was just the most awful experience because I would be watching what mood he was in, and then watch what my eldest daughter who's 21 might come out with which might antagonise the little one which then would antagonise Jack, so you are already watching what's going on with everybody's eye contact, body language, what mood they are in to make sure that that dinner situation was pleasant and didn't make Jack take something the wrong way or you know get him agitated so it's actually quite exhausting.

(Veronica)

\section{My wounded solider or a man behaving badly?}

This theme represented a central dilemma that the women were struggling with, namely, whether their partner was a 'good' man who was just sick and unwell or a 'bad' person who was acting in an abusive manner. This construction of their partners as either being sick or bad had a potent influence on how the women would consequently act and feel 
towards the veterans; it was acceptable to provide a sick man with care and nurturing, whereas if he was bad the probable conclusion would be divorce and for the women to acknowledge that they had married the wrong person. The fact that all of the women were currently still in their relationships at the time of the study - often requiring them to fight hard to have got to the point where they were - was almost certainly linked in part to the dominant construction across the interviews that the veterans with PTSD/trauma were indeed sick.

However, it appeared that the women who had got to the point where they had communicated to their partner that certain behaviour was unacceptable to them - even if the negative behaviour could be explained by PTSD - felt more secure and optimistic about their relationships. Although this idea of the men as being 'essentially good but behaving in a sick way' was key in helping the women continue on their caring role, some of the participants acknowledged that this was not a static process and they often seemed to vacillate between the two extreme views in trying to work out their partners' behaviour. Maria alluded to a dominant social narrative about veterans being 'heroes' - a theme discussed later - which contributed to the times in which she switched towards feeling that she should be more accommodating of her husband:

you swing wildly from like oh my God he's an absolute fucking cock-end and I can't stand him and he's awful maybe he hasn't got PTSD, he's just a twat (mm) to oh dear he's got PTSD, oh my God isn't it terrible, I should feel really awful for this bloke and go give him a kiss and a cup of tea and isn't it amazing, and he's a hero.

Receiving a psychiatric diagnosis, which for the majority included PTSD, was a significant event for most of the women in terms of their constructions of the struggles within their relationships. In some ways, it could be said that the diagnosis cemented the idea that the veteran was sick and therefore that the women should stay to look after him or be guiltridden if they decide to leave, as illustrated by Maria: "I have no issue with the girls that 
leave, to be honest. Sometimes I am quite jealous, cos it's like, you know- but then you've got the guilt of you left somebody who was quite ill”.

The women expressed relief that at least some of the undesirable elements of their partners' behaviour were now explained by a diagnostic label, meaning that it was not necessarily a permanent feature at the essence of the men's personalities:

And I didn't realise how many of his characteristics were relevant to the PTSD and the time he served, I just thought he could be an arrogant twat, but it turns out that there are lots of arrogant twats out there and there's a reason for it, that kind of makes sense... I was relieved because at least it meant he wasn't just an arrogant twat, there was a reason. (Caitlin)

For those women who were in a relationship with their partner before or during his military service (and commonly prior to the onset of trauma symptoms), the sickness construction held particular significance as they could recall a time when their partner was well and 'normal'. These women's accounts constructed a sense of loss and a grieving process for the husband that they no longer felt was there, to the extent that the new men were portrayed as being imposters. However in addition to being sick, these men were constructed as being essentially changed or damaged by their military experience, and some of the women were less optimistic that a cure would be possible:

And it's a very strange thing to, it's a bit like I've grieved my husband and I have completely grieved him, so many tears and so many heartaches and (.) but he is still in the garden, looking like him (mm) and that's hard because (yeah) if someone dies they die and go don't they, like my dad did, and you grieve and move on and but you are kind of in this massive limbo because he is there but it's not him, and will he ever come back $(\mathrm{mm}) ?$ (Veronica) 
“Being somebody's wife, mother, nursemaid, champion": Partners' attempts at negotiating multiple roles.

The women all constructed their experience of living with trauma as demanding that there was a shift in terms of the roles they occupied within their families and their relationships. This included feeling like a carer for their partner, which was strongly linked to the themes above about the veteran being sick and not able to fully function within the home, and also subduing their own responses to care for and make life as easy as possible for the veteran. Fulfilling a carer role involved a number of responsibilities such as organising their partner's daily routine and encouraging them to be active, assigning them tasks to do around the house, ensuring that they eat, take medication and go to bed on time, filling in benefit forms and compensation applications, providing a listening ear or trying to encourage them to talk about their worries. This change in role left some women, such as Mary, confused about their status within the couple, but they constructed taking on a more directive stance as being necessary for the continuation of the relationship:

that's been a really difficult battle cos it's a funny role to play cos it's not really mummy, it's not really care-ish, it's really not girlfriend... but I always knew that if I didn't battle on with some of the really trivial things like... you need to get up because I want to have a relationship with you and if you get up at one and go to bed at five am, I can't have a relationship with you because I won't see you. (Mary)

The women generally constructed the shift in roles as a process that occurred gradually over time, and some then suddenly realised the extent to which they had taken on carer-like duties. This was often accompanied by a change in some element of the power dynamic within the relationships, with the veterans' withdrawal from family life meaning that the women had to take charge. All of the women observed this change to some extent, with it 
seeming to have become more of an entrenched pattern for those participants who had lived with combat-related trauma for a significant number of years. The women constructed this shift in relational roles as being an undesirable situation, with many of the women wishing that it felt more balanced and that they were able to work as part of a team with their veteran partner.

In constructing their experiences, some of the participants took a critical stance towards dominant social narratives about the responsibilities of wives (to stand by their husbands wherever possible and sacrifice their own needs if required, with military wives being a more extreme version of this) and gendered role expectations that women should provide care and look after the household. For example, Thelma stated that "everything in the Army is all about how to support your husband, don't be a bad wife and make dramas... you know all these sacrifices but you don't get information back, nothing”.

Central to the shift in roles was the concept of over-functioning, whereby the women compensated for what their partner was unable to do by taking on additional roles, including those they had previously constructed as being 'a man's job'. For some, this meant that they were unsure as to whether the veteran had any household role left, but were unwilling to relent some of the responsibilities due to the perceived impact this would have on family life: well I just kind of, I just do everything. I just don't really assume he can do anything... it's really hard to get a balance because once again I could try and give some like control if you like back to Mark but then everything goes pear-shaped and I can't take that risk because everything's so difficult anyway. Erm and I think he's- he accepts that. (Elizabeth)

Some women assigned their partners certain roles around the house, which was found to be helpful in some cases, although others felt this worsened the veteran's distress and therefore the emotional load on the women. Others noticed that their partners were aware of 
this shift too, and were conscious of wanting to avoid prompting any further withdrawal in the veteran. Arguably, the women's best intentions in increasing their own input within the family may have been linked to the veteran's further withdrawal, as some veterans appeared to want to retain particular roles as if it was crucial for their identity and place within the home:

Now he-he stopped cutting the grass and it got really really really long but I wasn't allowed to cut the grass, because I was going to be taking another one of his jobs away from him. He'd got this thing that when he came out of the Army, I took away all his jobs (.) I didn't, because I actually wanted him to do more. (Veronica) I don't think you could take that [driving] away from him because he's actually in control of something there, as his little domain and I can't take that over and he knows that because I can't drive. (Jane)

For others, they constructed the whole process of being a caretaker and an advocate for their husbands as being a battle that they as partners were responsible for fighting. This was associated with regret and anger that the military and society did not seem to fully appreciate that the effects of combat-related trauma/PTSD were potentially long-lasting for the families of veterans, in addition to the primary trauma survivor himself. This is summed up by Hilary who took on the role of fighting for professional help: "he just isn't able to fight for it, which is what I end up having to do. And I shouldn't have to fight for services", and Jane who despite caring for her husband for over twenty years, still felt that she had to battle her way through the financial and health systems to support both her and her husband:

Paul's done his bit, I'm paying the price now, sounds selfish yes I know it does but I'm paying the price now for what he did, so I'm still fighting for this country to try and keep him going as much as I can. But like them, you can only fight for so long. You can't keep on and on and on because in the end you think right I'm going to give up. I 
can't be bothered anymore. And I have got to that stage but somehow I've just got back up there and I've started all over again, the fight. I do give up but nobody's going to give us anything, I've got to get out there and fight for it but I'm still fighting for the two of us. Not just fighting for one, it's both of us I'm fighting for. How long?

For the majority of the women, the consquence of juggling multiple roles, overfunctioning, trying to encourage their partner to participate in their parenting roles and in family life, and fighting for support not surprisingly led to them feeling burnt out and struggling with their own mental health difficulties. They constructed this situation as being a significant factor in how they personally were impacted by living with combat-related trauma, as their difficulties were seen as being directly linked to the veterans' issues:

It has just been incredibly wearing and I think it just finished me off, so yeah I ended up seeing the doctor quite a lot um and just the fatigue was just immense, so yeah they are treating me for chronic fatigue now, and then depression, what a surprise, cos I guess it has to rub off at some point, there are very few people who are totally immune to it all and I think I just got $y^{\prime}$ know engulfed in it all (Mary)

Heroes don't do the dishes: How constructing veterans as heroes impacts the maintenance of PTSD/trauma and family difficulties

The women were aware of a dominant social narrative that positioned veterans as heroes and employed this to construct their experience of the impact of combat-related trauma within their families. Commonly, this narrative was denigrated and rejected as being harmful to both them and their veteran partners. The women constructed this as putting veterans on a pedestal and giving the veterans an excuse to avoid the menial chores of family life, such that these jobs would be incongruent to someone who was wanting to maintain the sense of being a hero. Caitlin added to this by constructing her husband's identification with 
being a hero as potentially contributing to his difficulties, by increasing his isolation and inability to fully integrate into civilian life:

"I've done seven years for Queen and country", we're talking about a fucking dishwasher, I'm struggling to see the relevance here... He does have a superiority complex because he's done seven years for his Queen and country, it does mean it puts him a couple of rungs above everybody else. And the unfortunate thing is, is that nobody else out there sees it like that. So I wonder if that's what makes him even worse, wanting to wear it even more as a badge. I mean he literally would walk around with a badge on saying it to be honest. But nobody- as I just said, nobody out there really seems to give a damn. (Caitlin)

yeah hero doesn't want to go shopping in Tescos and sometimes it's not because it's an ordeal because its busy and whatever, it's because he's feeling a little bit in the hero balloon and now thinks that's a little bit beyond him (Mary)

Other women also alluded to the ignorance of wider society and the role this plays in propagating the heroisation of veterans. Outsiders were seen as seemingly unaware of the potential consequences of warfare - not just for the solider himself, but also for his family. Some women referenced the media's role in painting an idolised image of the military, and constructed this as having an impact on their own experiences of living with combat-related trauma. Specifically, they spoke about their annoyance that people expected them to be the dutiful wife and to do all they could for their hero husband, which perhaps prevented the reality of their home situation being acknowledged or appreciated:

... and you know there is a lot of this "Help the Heroes" thing going on, help the soldiers and lots of documentaries about helping the soldiers, and there is no documentaries on army wives, well there is nothing is there, so everybody feels sorry for the soldiers and "I hope you're giving him lots of support" and-and you think you 
have no idea, or we wouldn't be having this conversation right now, you'd be thinking maybe more like God that's awful, they don't give any of them any support you know. But I think it's all very in the papers about the actual men, nothing about the people behind them that are getting the abuse and the rubbish to pick up. (Veronica) The participants constructed different viewpoints about the impact the hero narrative had on the men. In one sense, it was regarded as being potentially adaptive and helpful at the time the men were serving, as it helped them to have the upmost confidence in their abilities and thus facilitated them being able to carry out such a difficult job. Alternatively, others constructed the 'heroisation' of military service personnel as being silencing, preventing their veteran partners from being able to show their vulnerability and seek help; as heroes are by definition strong and not in need of talking and support. Thelma alluded to an idea that silence is promoted by the military for a variety of reasons, and the heroisation of soldiers is employed to encourage this:

I believe that is how they train them to be, to be- keep it a secret, be proud of it what you've done, you're a man you're a tough soldier, you're a hero, they always call them heroes all the time. (Thelma)

Some women were angry that the military-focused interventions for PTSD/trauma appeared to reinforce being a hero and re-institutionalised the veterans, rather than preparing them better for family life. They were cynical of treatment centres that mirrored Army barracks, where meals were prepared and beds made for them, and where they lived once again within a military culture. Some women were of the opinion that support of this nature fed into the maintenance of their partners' PTSD as it served a function for them to be able to preserve their attachment to some element of the Army. Mary cautioned against input that encouraged the continuation of veterans' self-construction as a hero, as an unintended 
consequence of this was that it removed them further from family and civilian life, thus impeding their reintegration:

I think there is a real danger if they are not careful, of creating this sort of hero culture $(\mathrm{mm})$ and people feeling entitled... they seem to think that, because they have been cocooned by the charities and things you know "aren't I amazing because I am a hero and I wear my hero tee-shirt and I am telling myself I am a hero every day and everyone tells me how amazing I am, that um I don't need to do a job application like everybody else I think someone's just going to give me one". (Mary)

\section{"The Army were his family": Struggling with the transition to civilian life}

The women noted that an additional complicating factor in the expression of combatrelated trauma was that their partners were also struggling with adapting to civilian life since leaving the Forces. They were generally constructed as being ill-equipped for family and civilian life, with common themes including that the veterans were controlling, had OCD-like neatness, were unable to make their own decisions, and wanted to follow strict routines. The women reasoned that some of these characteristics may have been extremely adaptive in the Armed Forces (e.g. to follow orders rather than making their own decisions), but became problematic when transferred to living in a family. Having PTSD on top of these characteristics was seen as amplifying the extent that they were difficult to live with and as making change more difficult:

They haven't got a clue how to behave in Civvy Street. They still go to the pub, they still get drunk. But the thing is when they sober up, you've still got to think for yourself, you've still got to go home and you've still go to decide what you want to wear, where you want to go, what you're doing. You're not going to have a man bellowing at you saying right you're going to do this this and this and you go off and do it. (Jane) 
There was also discussion of the multitude of losses that veterans experience when leaving the Armed Forces, which was seen as a triggering factor for their PTSD/trauma symptoms. This included the loss of employment, structure, routine, friends, respect and authority, and a sense of purpose. Additionally, the military were constructed as fulfilling the function of the veteran's family, providing structure, containment and support which was a major benefit of serving in the Armed Forces:

...he had that release where he would go out and go down to the mess and relieve stress with mates in the Army, he doesn't have that any more. So it's almost as if you've been removed from the whole support network, essentially family (Hilary). ...the Army were his family. And then when he left the Army and he tried to make contact and people just didn't reciprocate, he kind of lost that. So I think that's hard because it's sort of dealing with a loss (Angela)

Some women took the idea further of the military as a surrogate family, constructing the system as providing an attachment figure or secure base for their partners throughout their formative years. In this sense, transitioning to civilian life in a way represented a painful separation from a structure that they had come to rely upon. Some of the women acknowledged that their partners had certain pre-existing vulnerabilities which for many of them was the reason they joined the Forces in the first place. This included the desire to escape an unhappy family situation where there was domestic violence or alcohol abuse, or to get away from dysfunctional relationships with parents:

And sometimes he'd be talking and just say "oh Sarge would be really happy with you for that". Like I do things and he'd be like "whoa yeah, you'd make Sergeant really happy". And of course sergeant to them was their dad, daddy figure, when they were being trained... in many ways Adam said he had to get away, he didn't have any 
options to stay at home, he didn't have anywhere to go... But he found a new family, when you talk about sergeant being the daddy-figure almost, and all your mates are part of your family. (Sabrina)

\section{DISCUSSION/CONCLUSION}

This study provided, to the best of the researcher's knowledge, the first qualitative investigation into how partners of UK military veterans constructed their experiences of living with combat-related trauma, carried out from a social constructionist perspective. We presented five themes which represented the relational, emotional and practical complexities the women and their families were living with on a daily basis, and the influence of social narratives on the way they made sense of their realities. These are discussed in turn below.

That the women felt it necessary to walk on eggshells has been reported elsewhere in the qualitative literature exploring the lived experiences of veterans' female partners in other countries (Verbosky \& Ryan, 1988; Outram et al., 2009), which was similarly understood as a way to prevent escalation of anger and conflict within relationships. Additionally, participants in the current study also reported wanting to protect their veteran partners from having to deal with the difficulties of everyday life and repressing their own emotional responses as a way to cope with their partner's unpredictability, which are also findings which have been reported elsewhere by female partners of veterans (Frederikson et al., 1996; Lyons, 2001). Difficulties in the reciprocal expression of emotions was apparent throughout the women's constructed stories. They referred to their partner's inability to tolerate emotions in other people and their withdrawal from situations where they were expected to comfort their wife or girlfriend. This meant that the women generally stopped approaching the veterans for emotional support, consequently leading them to feel that there was a lack of intimacy and reciprocity in their relationships. Emotional numbing and avoidance is a 
defining characteristic of PTSD as denoted by the DSM-5 (APA, 2013) and has been found to be related to reduced relationship satisfaction in both quantitative (Cook et al., 2004; Goff et al., 2009) and qualitative research studies (Frederikson et al., 1996; Dekel et al., 2005;

Outram et al., 2009; Nir et al., 2013). Of course, when positioned within an intimate relationship, avoidant behaviour will have an impact on how the other individual within the dyad will react. It could be said therefore that the women's strategy of walking on eggshells was in itself avoidant and in some situations unhelpful (albeit useful in others), perhaps even contributing to the maintenance of the difficulties. This unintentional reinforcement has been noted elsewhere (Monson, Taft, \& Fredman, 2009), although it seems important that this is approached sensitively when working with couples living with combat-related trauma.

As a consequence of subduing their own responses and feeling unsupported within their relationships, many of the women indicated that they were experiencing their own mental health difficulties. Importantly, although the women tended to construct their own difficulties as being linked to their veteran partners' issues, their descriptions were more in line with general distress (such as anxiety, depression, hopelessness, stress and burn-out) rather than suggestive of PTSD or secondary traumatic stress (STS). That is, they were less likely to describe experiences that mapped onto the PTSD diagnostic criteria of hyperarousal, re-experiencing and avoidance of reminders of a traumatic event. However as with Renshaw et al.'s (2011) sample, a few of the participants in the present study reported some 'symptoms' which mirrored their partners' PTSD symptoms. In particular, there was a sense that the women had developed hyper-vigilance as a strategy to manage everyday family life. However, instead of being related to past traumatic events, they were increasingly sensitive to their veteran partners' moods and behaviours, contributing to their sense of walking on eggshells. Hyper-vigilance of this nature was also reported in Gerlock et al.'s (2014) qualitative investigation into couples living with combat-related PTSD, emphasising the 
value of qualitative research in gaining insight into the subtleties and the meaning given to so-called symptoms. It may be the case that quantitative studies into secondary traumatisation in partners which employ measures of hypervigilance falsely conceptualise this as being directly linked to the veterans' primary trauma, rather than as a more general consequence of living with the effects of trauma on a daily basis.

Participants were able to take part in the study both if they met their veteran partner both whilst he was serving but also if they began their relationship when their partner was no longer serving. Those who had known their partner before he began to show symptoms of traumatisation were particularly likely to construct the veteran as being sick, as they had been aware of a time when he was by all accounts healthy and functioning well. In these cases, the concept of ambiguous loss (Boss, 1999) can help explain the women's sense of their partner being physically present but emotionally absent, an observation also reported in other qualitative studies of the experiences of veterans' partners (Frederikson et al., 1996; Dekel et al., 2005a; Outram et al., 2009; Nir et al., 2013).

This links to another area in which the present study provided a novel contribution: highlighting the social narratives about veterans, warfare and the military which the women made use of when constructing their own experiences of living with combat-related trauma in the UK. The theme named heroes don't do the dishes summarised this finding and suggested that the women were largely critical of the heroisation of veterans, as this portrayal of military men perhaps contributed to their husbands' difficulties in expressing vulnerability, getting involved in the mundane aspects of family life, and prevented them from being able to voice that, in reality, they felt anything but a hero. It seemed that some veterans had adopted the hero role in a defensive way, perhaps to minimise the extent to which they felt guilty or ambivalent about certain aspects of their military career. Arguably, the propagation of this narrative may also serve a psychologically defensive role for both the military and for 
society, making it easier to avoid the potential feelings of guilt from knowing that others' are putting their lives on the line for us - in a job that many of us would not want to do.

It is also of course important to remember though that, in the absence of hearing the veterans' voices directly, the narrative of veterans as heroes may well be something that many military personnel themselves feel uncomfortable with and wish to distance themselves from. Either way, it may be important for clinicians working with this population to be aware of dominant social narratives and how they may be affecting and maintaining the expression of difficulties within a particular family system. In this sense, the heroisation of veterans can be conceptualised as a potential maintaining factor of combat-related PTSD/trauma, to be considered alongside more typical maintaining factors such as avoidance and hyper-vigilance.

In the UK, MacManus and Wessely (2013) have also acknowledged the presence of a dominant discourse of veterans as heroes and reflected on its influence on mental health helpseeking behaviour in this population. They noted the disparity between the construct of veterans as strong, resilient and heroic and dominant discourses around mental health service users as being vulnerable, suffering and disempowered. This is likely to represent a significant leap in self-perception and is posited as one barrier preventing some veterans from seeking professional mental health support once responsibility for their care is transferred to the NHS. Indeed, in relation to the present findings, it may also have affected the type of intervention favoured by some veterans such that those which contained elements of military culture (such as accommodation similar to barracks) were seen as being further removed from civilian psychiatric institutions. Some women in the study constructed this as maintaining heroisation rather than facilitating the veterans' reintegration back into family life and wider civilian society. Although it is difficult to balance the need to provide veterans with treatment that will appeal to them and in which they will be more likely to engage, this 
study suggested that there is scope to better prepare veterans for the practical and emotional demands of family life. This perhaps could be incorporated into existing treatment programmes, or services may wish to develop more family-focused treatment options in which partners and children can be more actively involved.

The final theme within the present study related to the women's construction of the transition to civilian life as being a struggle, meaning that leaving the Forces involved multiple losses for their veteran partners which exacerbated their PTSD/trauma. This included loss of role, of status, of friendships, and the sense of family that military service had provided them. Other authors have also alluded to the huge adjustment that transition can demand on the whole family, which often means a reconfiguration of roles (Figley, 1993; Nelson \& Wright, 1996; Deahl et al., 2011). In the current study, the military and senior personnel were constructed as representing attachment figures for some of the men, providing the containment, security and boundaries that the women perceived their partners had not received enough of during childhood.

As mentioned earlier, self-reflexivity is central to the process of conducting qualitative research. The principal researcher reflected on how her position as a female and from a non-military background will have influenced the collection and interpretation of the data. There were moments in the interviews where the researcher felt invited into seeing elements of the difficulties as being 'male problems', and to feel strongly loyal to the female participant and disapproving of the male veterans, whose voices were not heard in this study. It was therefore crucial that the researcher was mindful that she was only hearing one side of the story and, in line with social constructionism, was not accessing the only reality or 'truth' about their relationships. This process was documented in the reflective diary. 
This study also had some limitations. The veterans themselves were not included in the research, meaning that their perspectives on the relational issues reported by their wives and girlfriends were not able to be heard. An area for future research could involve military husbands and wives being interviewed together about their relationships, which would allow for a more obviously systemic lens to be applied to understanding the relational experiences of these couples. The current study also did not manage to recruit any same-sex couples meaning that it has mirrored the heteronormativity found in the majority of the literature into military couples. Additionally, despite best attempts, the current study did not manage to recruit any male partners of female veterans.

In conclusion, the clinical implications of this research firstly relate to the importance of considering the veteran as being part of a relational and cultural system, rather than just as an individual. This not only means that partners should receive more support to benefit their own well-being, but that this would also in turn promote the mental health of the veteran. This is particularly pertinent as there is some evidence that veterans have indicated that their treatment priorities include support with relationships with partners and parenting children (Khaylis et al., 2011). Specifically this might involve: exploring couples' narratives about trauma, PTSD, the Armed Forces and transitioning to being civilian life; reframing traumatisation as a relational as well as individual experience; and helping them to communicate about the impact that living with trauma has had on their couple or family dynamic and working towards what they might want to be different (practically, emotionally, or otherwise). Reintegration into wider society and to the family is such an important task, and given that support with this tends to lie with veterans' partners (Gerlock et al., 2014), it makes practical and clinical sense to invest more in building the resilience of partners and other family members, and in strengthening relationships. 


\section{REFERENCES}

American Psychiatric Association. (2000). Diagnostic and Statistical Manual of Mental Disorders (4 ed. vol. text. revised). Washington, DC: American Psychiatric Association.

American Psychiatric Association. (2013). Diagnostic and Statistical Manual of Mental Disorders (5 ed.). Washington, DC: American Psychiatric Association.

Arzi, N. B., Solomon, Z., \& Dekel, R. (2000). Secondary traumatization among wives of PTSD and post-concussion casualties: Distress, caregiver burden and psychological separation. Brain Injury, 14(8), 725-736.

Baddeley, J. L., \& Pennebaker, J. W. (2011). A postdeployment expressive writing intervention for military couples: a randomized controlled trial. Journal of Trauma Stress, 24(5), 581-585.

Boss, P. (1999). Ambiguous loss: living with frozen grief. The Harvard Mental Health Letter, 16(5), 4-7.

Braun, V., \& Clarke, V. (2006). Using thematic analysis in psychology. Qualitative Research in Psychology, 3(2), 77-101. doi: 10.1191/1478088706qp063oa

Braun, V., \& Clarke, V. (2012). Thematic analysis. In H. Cooper (Ed.), APA Handbook of Research Methods in Psychology (Vol. 2, pp. 57-71). USA: American Psychological Association.

Braun, V., \& Clarke, V. (2013). Successful qualitative research: A practical guide for beginners. London: Sage Publications.

Browne, T., Hull, L., Horn, O., Jones, M., Murphy, D., Fear, N. T., . . Hotopf, M. (2007). Explanations for the increase in mental health problems in UK reserve forces who have served in Iraq. British Journal of Psychiatry, 190, 484-489. doi:

10.1192/bjp.bp.106.030544 
Burr, V. (2003). Social constructionism (2nd edition ed.). East Sussex: Routledge.

Calhoun, P. S., Beckham, J. C., \& Bosworth, H. B. (2002). Caregiver burden and psychological distress in partners of veterans with chronic posttraumatic stress disorder. Journal of Traumatic Stress, 15(3), 205-212.

Campbell, S. B., \& Renshaw, K. D. (2012). Distress in spouses of Vietnam veterans: associations with communication about deployment experiences. Journal of Family Psychology, 26(1), 18-25. doi: 10.1037/a0026680

Campbell, S. B., \& Renshaw, K. D. (2013). PTSD symptoms, disclosure, and relationship distress: explorations of mediation and associations over time. Journal of Anxiety Disorders, 27(5), 494-502. doi: 10.1016/j.janxdis.2013.06.007

Cook, J. M., Riggs, D. S., Thompson, R., Coyne, J. C., \& Sheikh, J. I. (2004). Posttraumatic Stress Disorder and Current Relationship Functioning Among World War II ExPrisoners of War. Journal of Family Psychology, 18(1), 36-45. doi: 10.1037/08933200.18 .1 .36

Deahl, M. P., Klein, S., \& Alexander, D. A. (2011). The costs of conflict: meeting the mental health needs of serving personnel and service veterans. International Review of Psychiatry, 23(2), 201-209. doi: 10.3109/09540261.2011.557059

Dekel, R., Enoch, G., \& Solomon, Z. (2008). The contribution of captivity and post-traumatic stress disorder to marital adjustment of Israeli couples. Journal of Social \& Personal Relationships, 25(3), 497-510.

Dekel, R., Goldblatt, H., Keidar, M., Solomon, Z., \& Polliack, M. (2005). Being a wife of a veteran with posttraumatic stress disorder. Family Relations, 54(1), 24-36.

Dekel, R., \& Monson, C. M. (2010). Military-related post-traumatic stress disorder and family relations: Current knowledge and future directions. Aggression and Violent Behavior, 15(4), 303-309. doi: 10.1016/j.avb.2010.03.001 
Dekel, R., Siegel, A., Fridkin, S., \& Svetlitzky, V. (2017). The double-edged sword: The role of empathy in military veterans' partners distress. Psychological Trauma: Theory, Research, Practice, and Policy, doi: 10.1037/tra0000265. [Epub ahead of print].

Dekel, R., Solomon, Z., \& Bleich, A. (2005). Emotional distress and marital adjustment of caregivers: contribution of level of impairment and appraised burden. Anxiety, Stress, \& Coping, 18(1), 71-82. doi: 10.1080/10615800412336427

Dirkzwager, A. J., Bramsen, I., Ader, H., \& van der Ploeg, H. M. (2005). Secondary traumatization in partners and parents of Dutch peacekeeping soldiers. Journal of Family Psychology, 19(2), 217-226. doi: 10.1037/0893-3200.19.2.217

Figley, C. R. (1983). Catastrophes: An overview of family reactions. In C. R. Figley \& H. I. McCubbin (Eds.), Stress and the family, Vol. II: Coping with catastrophe (pp. 3 - 20). New York: Brunner/Mazel.

Figley, C. R. (1986). Traumatic stress: The role of the family and social support system. In C. R. Figley (Ed.), Trauma and its wake (Vol. II: Traumatic stress theory, research and intervention) (pp. 39 - 54). New York: Brunner/Mazel.

Figley, C. R. (1993). Coping with Stressors on the Home Front. Journal of Social Issues, 49(4), 51-71. doi: 10.1111/j.1540-4560.1993.tb01181.x

Figley, C. R. (1995). Compassion fatigue as secondary traumatic stress disorder: An overview. In C. R. Figley (Ed.), Compassion fatigue: Coping with secondary traumatic stress disorder in those who treat the traumatised (pp. 1 - 20). New York: Routledge.

Figley, C. R., \& Figley, K. R. (2009). Stemming the tide of trauma systemically: The role of family therapy. Australian and New Zealand Journal of Family Therapy, 30(03), $173-$ 183. 
Fossey, M. (2012). Unsung heroes: Developing a better understanding of the emotional support needs of Service families. London: Centre for Mental Health.

Frančišković, T., Stevanović, A., Jelušić, I., Roganović, B., Klarić, M., \& Grković, J. (2007). Secondary traumatization of wives of war veterans with posttraumatic stress disorder. Croatian Medical Journal, 48(2), 0-184.

Frederikson, L. G., Chamberlain, K., \& Long, N. (1996). Unacknowledged Casualties of the Vietnam War: Experiences of Partners of New Zealand Veterans. Qualitative Health Research, 6(1), 49-70. doi: 10.1177/104973239600600104

Galovski, T., \& Lyons, J. A. (2004). Psychological sequelae of combat violence: A review of the impact of PTSD on the veteran's family and possible interventions. Aggression and Violent Behavior, 9(5), 477-501. doi: 10.1016/s1359-1789(03)00045-4

Gerlock, A. A., Grimesey, J., \& Sayre, G. (2014). Military-related posttraumatic stress disorder and intimate relationship behaviors: a developing dyadic relationship model. Journal Of Marital and Family Therapy, 40(3), 344-356. doi: 10.1111/jmft.12017

Gilbert, K. (1997). Understanding the secondary traumatic stress of spouses. In C. R. Figley (Ed.), Burnout in families: The systemic cost of caring (pp. 47 - 73). USA: CRC Press.

Goff, B. S., Crow, J. R., Reisbig, A. M., \& Hamilton, S. (2007). The impact of individual trauma symptoms of deployed soldiers on relationship satisfaction. Journal of Family Psychology, 21(3), 344-353. doi: 10.1037/0893-3200.21.3.344

Goff, B. S. N., \& Smith, D. B. (2005). Systemic traumatic stress: The couple adaptation to traumatic stress model. Journal of Marital and Family Therapy, 31(2), 145-157.

Goff, B. S. N., Crow, J. R., Reisbig, A. M., \& Hamilton, S. (2009). The impact of soldiers' deployments to Iraq and Afghanistan: Secondary traumatic stress in female partners. Journal of Couple \& Relationship Therapy, 8(4), 291-305. 
Jones, E., \& Wessely, S. (2007). A paradigm shift in the conceptualization of psychological trauma in the 20th century. Journal of Anxiety Disorders, 21(2), 164-175. doi: 10.1016/j.janxdis.2006.09.009

Khaylis, A., Polusny, M. A., Erbes, C. R., Gewirtz, A., \& Rath, M. (2011). Posttraumatic stress, family adjustment, and treatment preferences among National Guard soldiers deployed to OEF/OIF. Military Medicine, 176(2), 126-131.

Klarić, M., Frančišković, T., Pernar, M., Nemčić Moro, I., Milićević, R., Černi Obrdalj, E., \& Salčin Satriano, A. (2010). Caregiver burden and burnout in partners of war veterans with post-traumatic stress disorder. Collegium Antropologicum, 34(1), 15-21.

Klarić, M., Kvesić, A., Mandić, V., Petrov, B. \& Francišković, T. (2013). Secondary traumatisation and systemic traumatic stress. Medicina Academica Mostariensia, 1(1), 29-36.

Koić, E., Francišković, T., Mužinić-Masle, L., Đorđević, V., Vondraček, S., \& Prpić, J. (2002). Chronic pain and secondary traumatization in wives of Croatian war veterans treated for post traumatic stress disorder. Acta Clinica Croatica, 41(4), 295-306.

Lambert, J. E., Engh, R., Hasbun, A., \& Holzer, J. (2012). Impact of posttraumatic stress disorder on the relationship quality and psychological distress of intimate partners: A meta-analytic review. Journal of Family Psychology, 26(5), 729.

Lyons, M. A. (2001). Living with post-traumatic stress disorder: the wives'/female partners' perspective. Journal of Advanced Nursing, 34(1), 69-77.

MacDonell, G. V., Thorsteinsson, E. B., Bhullar, N., \& Hine, D. W. (2014). Psychological functioning of partners of Australian combat veterans: Contribution of veterans' PTSD symptoms and partners' caregiving distress. Australian Psychologist, 49(5), 305-312. doi: 10.1111/ap.12069 
MacManus, D., \& Wessely, S. (2013). Veteran mental health services in the UK: are we headed in the right direction? Journal of Mental Health, 22(4), 301-305. doi: $10.3109 / 09638237.2013 .819421$

Maloney, L. J. (1988). Post traumatic stresses on women partners of Vietnam veterans. Smith College Studies in Social Work, 58(2), 122-143. doi: 10.1080/00377318809516639

Maltas, C. (1996). Reenactment and Repair: Couples Therapy with Survivors of Childhood Sexual Abuse. Harvard Review of Psychiatry, 6, 351-355.

Manguno-Mire, G., Sautter, F., Lyons, J., Myers, L., Perry, D., Sherman, M., . . Sullivan, G. (2007). Psychological distress and burden among female partners of combat veterans with PTSD. The Journal of Nervous and Mental Disease, 195(2), 144-151.

Mays, N., \& Pope, C. (2000). Assessing quality in qualitative research. British Medical Journal, 320(7226), 50-52.

McCormack, L., Hagger, M. S., \& Joseph, S. (2010). Vicarious growth in wives of Vietnam veterans: A phenomenological investigation into decades of "lived" experience.

Monson, C. M., Taft, C. T., \& Fredman, S. J. (2009). Military-related PTSD and intimate relationships: From description to theory-driven research and intervention development. Clinical Psychology Review, 29(8), 707-714. doi: 10.1016/j.cpr.2009.09.002

Murphy, D., Palmer, E., \& Busittil, W. (2016). Mental health difficulties and help-seeking beliefs within a sample of female partners of UK veterans diagnosed with posttraumatic stress disorder. Journal of Clinical Medicine, 5, 68; doi: $10.3390 /$ jem5080068

Nelson, B. S., \& Wright, D. W. (1996). Understanding and treating post-traumatic stress disorder symptoms in female partners of veterans with PTSD. Journal of Marital and Family Therapy, 22(4), 455-467. 
Nir, M. S., Ebadi, A., Khoshknab, M. F., \& Tavallaie, A. (2013). Experiences of wives of veterans suffering from combat-related post-traumatic stress disorder: A qualitative content analysis. International Journal of Community Based Nursing and Midwifery, $1(3), 147-155$.

Outram, S., Hansen, V., MacDonell, G., Cockburn, J. D., \& Adams, J. (2009). Still living in a war zone: perceived health and wellbeing of partners of Vietnam veterans attending partners' support groups in New South Wales, Australia. Australian Psychologist, $44(2), 128-135$.

Renshaw, K. D., Allen, E. S., Rhoades, G. K., Blais, R. K., Markman, H. J., \& Stanley, S. M. (2011). Distress in spouses of service members with symptoms of combat-related PTSD: secondary traumatic stress or general psychological distress? Journal of Family Psychology, 25(4), 461-469. doi: 10.1037/a0023994

Solomon, Z., Dekel, R., Zerach, G., \& Horesh, D. (2009). Differentiation of the self and posttraumatic symptomatology among ex-POWs and their wives. Journal Of Marital And Family Therapy, 35(1), 60-73. doi: 10.1111/j.1752-0606.2008.00102.x

Summerfield, D. (2001). The invention of post-traumatic stress disorder and the social usefulness of a psychiatric category. BMJ, 322(7278), 95-98.

Vagharseyyedin, S. A. (2014). Experiences of wives of Iranian war veterans with posttraumatic stress disorder regarding social relationships. Public Health Nursing $32(2), 122-131$.

Verbosky, S. J., \& Ryan, D. A. (1988). Female partners of Vietnam veterans: stress by proximity. Issues in Mental Health Nursing, 9(1), 95-104.

Westerink, J., \& Giarratano, L. (1999). The impact of posttraumatic stress disorder on partners and children of Australian Vietnam veterans. Australian and New Zealand Journal of Psychiatry, 33(6), 841-847. 


\begin{tabular}{lcc}
\hline \multicolumn{3}{l}{ Table 1} \\
\multicolumn{1}{l}{ Demographic Information } & about Partners and Veterans \\
\cline { 1 - 2 } Demographics & $\underline{\text { Partners }(N=15)}$ & Veterans $(N=15)$ \\
\cline { 2 - 3 } Age & $42(S D=11.7)$ & $43(S D=12.8)$ \\
Mean age (years) & $26-69$ & $29-69$ \\
Age range (years) & $13(86.6 \%)$ & $13(86.6 \%)$ \\
Ethnicity & $1(6.7 \%)$ & $0(0 \%)$ \\
White British & $0(0 \%)$ & $1(6.7 \%)$ \\
British Asian & $1(6.7 \%)$ & $0(0 \%)$ \\
Mixed White & $0(0 \%)$ & $1(6.7 \%)$ \\
British/Asian & & \\
Mixed White/Black & & \\
Other (Fijian) & & \\
Black Other (Fijian) & &
\end{tabular}

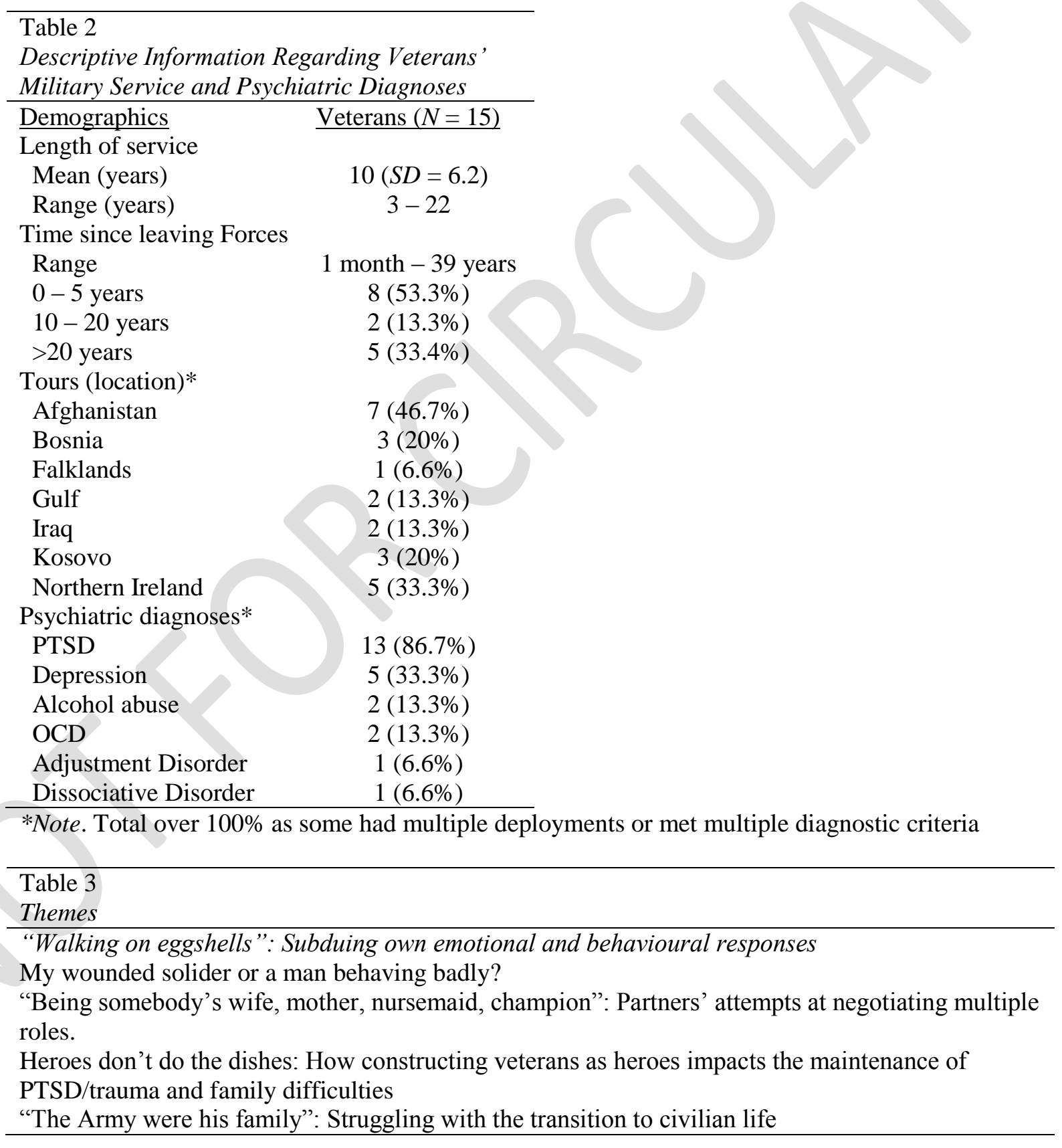

